\title{
Safe and Efficient Discharge in Bronchiolitis: How Do We Get There?
}

\author{
Patrick W. Brady, MD, MSc*, Amanda C. Schondelmeyer, MD
}

Division of Hospital Medicine, James M. Anderson Center for Health Systems Excellence, Department of Pediatrics, Cincinnati Children's Hospital Medical Center, Cincinnati, Ohio.

Bronchiolitis is the most common cause of hospitalization in infancy, with estimated annual US costs of over $\$ 1.7$ billion. ${ }^{1}$ The last 2 decades have seen numerous thoughtful and well-designed research studies but little improvement in the value of care. ${ }^{1-4}$ The diagnosis and treatment section of the recently released 2014 American Academy of Pediatrics (AAP) Clinical Practice Guideline for bronchiolitis contains 7 "should not's" and 3 "should's," 3 with the only clear affirmative recommendations related to the history and physical and to the use of supplemental fluids. As supported by several systematic reviews and randomized controlled trials, the use of respiratory treatments, including $\beta$-agonists, racemic epinephrine, and hypertonic saline, was discouraged. There continues to be significant variation in care for patients with bronchiolitis ${ }^{5,6}$ and rigorous evidence was lacking on when a child could be safely discharged home.

Mansbach and colleagues in the Multicenter Airway Research Collaboration (MARC-30) provide the best evidence to date on the clinical course of bronchiolitis and present multicenter data upon which to build evidence-based discharge criteria. ${ }^{7}$ In their prospective cohort study of 16 US children's hospitals, Mansbach et al. sought to answer 3 research questions: (1) In infants hospitalized with bronchiolitis, what is the time to clinical improvement? (2) What is the risk of clinical worsening after standardized improvement criteria are met? (3) What discharge criteria might balance both timely discharge and very low readmission risk? In an analytic cohort of 1916 children $<2$ years of age with a physician diagnosis of bronchiolitis, the time from onset of difficulty breathing until clinical improvement was a median of 4 days, with a 75 th percentile of 7.5 days. Of the 1702 children who clinically improved before discharge, only $76(4 \%)$ then worsened. Although there are some limitations to how these criteria were assessed, the authors' work supports discharge criteria of (1) no or mild and stable or

*Address for correspondence and reprint requests: Patrick W. Brady, MD, Cincinnati Children's Hospital, ML 9016, 3333 Burnet Avenue, Cincinnati, OH 45229; Telephone: 513-636-3635; Fax: 513-636-4402; E-mail: patrick.brady@cchmc.org

Additional Supporting Information may be found in the online version of this article.

Received: December 15, 2014; Revised: December 29, 2014; Accepted: January 2, 2015

2015 Society of Hospital Medicine DOI 10.1002/jhm.2323

Published online in Wiley Online Library (Wileyonlinelibrary.com). improving retractions, (2) stable or improving respiratory rate that is below the 90th percentile for age, (3) estimated room air saturation of $\geq 90 \%$ without any points $<88 \%$, and (4) clinician assessment of the child maintaining adequate oral hydration, regardless of use of intravenous fluids.

Three limitations warrant consideration when interpreting the study results. First, the MARC-30 investigators oversampled from the intensive care unit and excluded 109 children with a hospital length of stay (LOS) $<1$ day. Although it is uncertain what effect these decisions would have on worsening after improving, both would overestimate the LOS in the sampled population at study hospitals. It is likely that the median LOS and 75th percentile of 4 and 7.5 days, respectively, are higher than what hospital medicine physicians saw at these hospitals. Second, the study team did not use a scoring tool. The authors note that the holistic assessments clinicians used to estimate respiratory rate and oxygen saturation "may be more similar to standard clinical practice more than a calculated mean." This raises an important question: If less numerous data might lead to more information and knowledge, might they also lead to reliability and validity concerns? Given an absence of a structured, validated assessment of these severity indicators, it seems possible clinicians worked "backward" from the holistic assessment of "this child is ready to go home" and then entered data to support their larger assessment. This would tend to bias toward lower proportions of worsening after clinical improvement. Third, the oncedaily review of the medical record led to less precise estimates of each event including time from difficulty breathing to improvement and LOS. In addition to the absence of a scoring tool, this likely adds a modest bias toward underdetection of clinical worsening after improvement, because observations from discharged children were effectively censored from analysis. Importantly the low readmission rates suggest neither of those biases is substantial.

Several of the findings in this article support recent changes to the recommendations in the 2014 AAP Bronchiolitis Clinical Practice Guideline. ${ }^{3}$ Although there is no recommendation on discharge readiness, Mansbach and colleagues found that an operationalization of the core criteria outlined in the 2006 version of the AAP Bronchiolitis Clinical Practice Guideline would result in a low proportion of subsequent clinical worsening. ${ }^{8}$ This study also informs and supports 
an additional change to the AAP's 2006 guideline recommendation on continuous pulse oximetry. Key Action Statement 6b in the 2014 guideline notes "Clinicians may choose not to use continuous pulse oximetry for infants and children with a diagnosis of bronchiolitis," expanding the recommendation from the 2006 guideline discouraging continuous pulse oximetry "as the child's clinical course improves." 3,8 Mansbach and colleagues found that removing the lower desaturation threshold of $\geq 88 \%$ improved the percentage of children who met criteria, with no changes in proportion subsequently worsening. With an improvement criterion of average oxygen saturation threshold of $95 \%$, less than half of the children met this criteria before discharge, and an increased percentage $(5 \%)$ clinically worsened, presumably due to clinically inconsequential "desaturations" to $94 \%$. The less stringent the pulse oximetry criteria, the better their improvement criteria performed. This study adds to the modest literature on how overuse of continuous pulse oximetry may prolong hospitalization, leading to non-value-added care and potentially increasing the risk of iatrogenic harm. ${ }^{9-11}$

Another strength of this study is the extensive viral testing on nasal aspirates. The absence of an association between individual viral pathogen or coinfection on the risk of worsening after improving further supports the recommendation against viral testing. The authors also identified a large group of children with a very low risk of worsening after an improving course: children $\geq 2$ months, born at term, and who did not present with severe retractions. This finding, which will resonate with clinicians who care for patients with bronchiolitis, provides additional data on a group likely to have short hospitalization and unlikely to benefit from therapies. It also identifies a group of children with increased risk of worsening, which could be targeted for future research efforts on therapies such as hypertonic saline and high-flow nasal cannula, where the evidence is mixed and inconclusive.

Both the MARC-30 study and the 2014 AAP guidelines are tremendous contributions to the scientific literature on this common, costly, and often frustrating disease for clinicians and families alike. More important, however, will be implementation and dissemination efforts to ensure children benefit from this new knowledge. After the 2006 AAP guidelines, there was some evidence of improved care ${ }^{12}$ but remaining profound hospital-level variation. ${ }^{5}$ Immediate next steps to improve bronchiolitis care should include interventions to standardize evidence-based discharge criteria and reduce the overuse of non-evidence-based care. Local clinical practice guidelines aid in the early phases of standardization, but without work and willpower in the implementation and sustain phase, their effect may be modest. ${ }^{13}$ This study and the new guideline raise several important "T3" 14 or "how" questions for pediatric hospital medicine clinicians, researchers, and improvers. First, how can evidencebased discharge criteria, such as those presented here, be applied reliably and broadly at the point of care? White and colleagues at Cincinnati shared a strategy that will benefit from further testing and adaptation. ${ }^{15}$ Second, how can continuous pulse oximetry be either greatly reduced or have its data put in a broader context to inform decision making? Relatedly, which strategy is more effective and for whom? Finally, what incentives at the hospital and policy level are most effective in helping physicians to "choose wisely" ${ }^{16}$ and do less?

Answering these questions will be crucial to ensure the knowledge produced from Mansbach and colleagues benefits the hundreds of thousands of children hospitalized with bronchiolitis each year.

\section{Disclosure}

Nothing to report.

\section{References}

1. Hasegawa K, Tsugawa Y, Brown DF, Mansbach JM, Camargo CA Jr. Trends in bronchiolitis hospitalizations in the United States, 20002009. Pediatrics. 2013;132(1):28-36.

2. Shay DK, Holman RC, Newman RD, Liu LL, Stout JW, Anderson LJ. Bronchiolitis-associated hospitalizations among US children, 19801996. JAMA. 1999;282(15):1440-1446.

3. Ralston SL, Lieberthal AS, Meissner HC, et al. Clinical practice guideline: the diagnosis, management, and prevention of bronchiolitis. Pediatrics. 2014;134(5):e1474-e1502.

4. Shay DK, Holman RC, Roosevelt GE, Clarke MJ, Anderson LJ. Bronchiolitis-associated mortality and estimates of respiratory syncytial virus-associated deaths among US children, 1979-1997. J Infect Dis. 2001;183(1):16-22.

5. Florin TA, Byczkowski T, Ruddy RM, Zorc JJ, Test M, Shah SS. Variation in the management of infants hospitalized for bronchiolitis persists after the 2006 American Academy of Pediatrics bronchiolitis guidelines. J Pediatr. 2014;165(4):786-792.e781.

6. Cheung CR, Smith H, Thurland K, Duncan H, Semple MG. Population variation in admission rates and duration of inpatient stay for bronchiolitis in England. Arch Dis Child. 2013;98(1):57-59.

7. Mansbach JM, Clark S, Piedra PA, et al.; MARC-30 Investigators. Hospital course and discharge criteria for children hospitalized with bronchiolitis. J Hosp Med. 2015;10(4):205-211.

8. American Academy of Pediatrics Subcommittee on Diagnosis and Management of Bronchiolitis. Diagnosis and management of bronchiolitis. Pediatrics. 2006;118(4):1774-1793.

9. Schroeder AR, Marmor AK, Pantell RH, Newman TB. Impact of pulse oximetry and oxygen therapy on length of stay in bronchiolitis hospitalizations. Arch Pediatr Adolesc Med. 2004;158(6):527-530.

10. Cunningham S, McMurray A. Observational study of two oxygen saturation targets for discharge in bronchiolitis. Arch Dis Child. 2012; 97(4):361-363

11. McBride SC, Chiang VW, Goldmann DA, Landrigan CP. Preventable adverse events in infants hospitalized with bronchiolitis. Pediatrics. 2005;116(3):603-608.

12. Parikh K, Hall M, Teach SJ. Bronchiolitis management before and after the AAP guidelines. Pediatrics. 2014;133(1):e1-e7.

13. Mittal V, Hall M, Morse R, et al. Impact of inpatient bronchiolitis clinical practice guideline implementation on testing and treatment. J Pediatr. 2014;165(3):570-576.e573.

14. Dougherty D, Conway PH. The "3T's" road map to transform US health care: the "how" of high-quality care. JAMA. 2008;299(19): 2319-2321.

15. White CM, Statile AM, White DL, et al. Using quality improvement to optimise paediatric discharge efficiency. BMJ Qual Saf. 2014;23(5): 428-436.

16. Quinonez RA, Garber MD, Schroeder AR, et al. Choosing wisely in pediatric hospital medicine: five opportunities for improved healthcare value. J Hosp Med. 2013;8(9):479-485. 